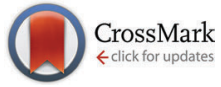

Cite this: J. Mater. Chem. C, 2015, 3, 5474

Received 4th February 2015, Accepted 18th April 2015

DOI: $10.1039 / c 5 t c 00346 f$

www.rsc.org/MaterialsC

\section{NIR optical carbon dioxide sensors based on highly photostable dihydroxy-aza-BODIPY dyes $\dagger$}

\author{
Susanne Schutting, ${ }^{a}$ Tijana Jokic, ${ }^{a}$ Martin Strobl, ${ }^{a}$ Sergey M. Borisov, ${ }^{\star a}$ Dirk de Beer $^{b}$ \\ and Ingo Klimant ${ }^{a}$
}

A new class of $\mathrm{pH}$-sensitive indicator dyes for optical carbon dioxide sensors based on di-OH-azaBODIPYs is presented. These colorimetric indicators show absorption maxima in the near infrared range $\left(\lambda_{\max } 670-700 \mathrm{~nm}\right.$ for the neutral form, $\lambda_{\max } 725-760 \mathrm{~nm}$ for the mono-anionic form, $\lambda_{\max } 785-830 \mathrm{~nm}$ for the di-anionic form), high molar absorption coefficients of up to $77000 \mathrm{M}^{-1} \mathrm{~cm}^{-1}$ and unmatched photostability. Depending on the electron-withdrawing or electron-donating effect of the substituents the $\mathrm{p} K_{\mathrm{a}}$ values are tunable (8.7-10.7). Therefore, optical carbon dioxide sensors based on the presented dyes cover diverse dynamic ranges $(0.007-2 \mathrm{kPa} ; 0.18-20 \mathrm{kPa}$ and $0.2-100 \mathrm{kPa})$, which enables different applications varying from marine science and environmental monitoring to food packaging. The sensors are outstandingly photostable in the absence and presence of carbon dioxide and can be read out via absorption or via the luminescence-based ratiometric scheme using the absorption-modulated inner-filter effect. Monitoring of the carbon dioxide production/consumption of a Hebe plant is demonstrated.

\section{Introduction}

Carbon dioxide is one of the most important parameters in many scientific and industrial fields, such as medicine, ${ }^{1-3}$ marine science, ${ }^{4-7}$ food packaging, ${ }^{8}$ bio processing ${ }^{9,10}$ or environmental and industrial monitoring. ${ }^{11}$ Routine techniques of $\mathrm{CO}_{2}$ quantification like infrared (IR) spectroscopy, gas chromatography (GC) or the Severinghaus electrode are well established, but suffer from different drawbacks. ${ }^{12,13}$ For instance IR spectroscopy is mainly used for gas samples, ${ }^{14,15}$ because of strong interferences of water and the Severinghaus electrode is strongly affected by osmotic effects. Carbon dioxide chemosensors are a promising alternative, ${ }^{16-23}$ among which the so-called "plastic type" sensors are the most common ones. ${ }^{24-31}$ The core of this type of sensor is a pH-sensitive indicator dye. It is embedded in a polymer matrix together with a base (mainly a quaternary ammonium base) and responds to carbon dioxide by changing its spectral properties according to the degree of protonation. Read-out of these sensors can be carried out via absorption or luminescence intensity. In the case of a fluorescent

\footnotetext{
${ }^{a}$ Institute of Analytical Chemistry and Food Chemistry, Graz University of Technology, NAWI Graz, Stremayrgasse 9, 8010 Graz, Austria.

E-mail: sergey.borisov@tugraz.at; Fax: +43316873 32502;

Tel: +4331687332516

${ }^{b}$ Max-Planck-Institute of Marine Microbiology, Celsiusstrasse 1, 28359 Bremen, Germany

$\dagger$ Electronic supplementary information (ESI) available: ${ }^{1} \mathrm{H}$ NMR and mass spectra for the di-OH-aza-BODIPY dyes. Details on sensing properties. See DOI: 10.1039/c5tc00346f
}

indicator dye, referencing of the fluorescence intensity is necessary to achieve reliable results. This can be realized by using an analyte-insensitive reference dye with different spectral properties from the indicator, either a different emission spectrum or a different luminescence decay time. Although necessary in many cases, the addition of reference materials can cause dramatic ratio changes when photobleaching of one dye (reference or indicator) or both occurs. Therefore, selfreferencing indicator dyes are highly desired for ratiometric read-out. However, only a few self-referencing dyes (absorption and fluorescence intensity) have been published so far. ${ }^{32-38}$ Optical carbon dioxide sensors are also of great interest in biological applications.

Here, indicators with absorption/fluorescence intensity maxima in the infrared (IR) or near-infrared (NIR) region are preferred, because of several advantages, e.g. low light scattering, dramatically reduced autofluorescence and availability of low-cost excitation sources and photodetectors. Recently our group has presented $\mathrm{pH}$-sensitive $\mathrm{BF}_{2}$-chelated tetraarylazadipyrromethene indicators (aza-BODIPYs). ${ }^{38}$ This indicator class represents an interesting alternative to the state-of-the-art dyes for biological applications as SNARF indicators ${ }^{39}$ or cyanine dyes. ${ }^{40,41}$ The aza-BODIPYs showed absorption/fluorescence intensity spectra in the near-infrared region and were highly photostable. Although $\mathrm{pH}$-sensitive, these dyes could not be used for optical carbon dioxide sensors. Here, the formation of the ion pair was irreversible and the indicator could not be protonated anymore, even at $100 \% \mathrm{CO}_{2}$. In this study we present a new class of $\mathrm{pH}$-sensitive indicator dyes suitable for 
optical carbon dioxide sensors, the di-OH-aza-BODIPYs containing two de-/protonatable hydroxyl groups. It will be shown that the $\mathrm{p} K_{\mathrm{a}}$ values of the di-OH-aza-BODIPYs can be tuned by using different substituents with either the electronwithdrawing or the electron-donating effect. Luminescence-based ratiometric read-out can be realized via the absorptionmodulated inner-filter effect. ${ }^{42-45}$ An application example demonstrating the carbon dioxide production/consumption of a Hebe plant will also be presented.

\section{Experimental}

\section{Materials}

Ethyl cellulose (EC49, ethoxyl content 49\%), thymol-blue (A.C.S. reagent), $m$-cresol-purple (indicator grade), poly(styrene-codivinylbenzene)microspheres ( $8 \mu \mathrm{m}$ mean particle size; PSmicroparticles), $3^{\prime}$-chloro-4'-hydroxyacetophenone, ammonium acetate, benzaldehyde, $N, N$-diisopropylethylamine (DIPEA), dry dichloromethane, boron trifluoride diethyl etherate, MOPS buffer salt, sodium sulfate (anhydrous) and tetraoctylammonium hydroxide solution (TOAOH, 20\% in methanol) were obtained from Sigma-Aldrich (www.sigmaaldrich.com). Deuterated dimethyl sulfoxide (DMSO- $d_{6}$ ) was purchased from Eurisotop (www.eurisotop.com). Perfluorodecalin (98\%; cis and trans), 1-butanol $(99 \%, \mathrm{BuOH})$ and nitromethane were received from ABCR (Germany, www.abcr.de), Hyflon AD 60 from Solvay (www.solvay.com). Nitrogen, $2 \%$ oxygen in nitrogen, $5 \%$ carbon dioxide in nitrogen, $0.2 \%$ carbon dioxide in nitrogen, argon and carbon dioxide (all of 99.999\% purity) were obtained from Air Liquide (Austria, www.airliquide.at). Toluene, ethanol (EtOH), tetrahydrofuran (THF), hydrochloric acid (37\%), dichloromethane (DCM) and hexane were purchased from VWR (Austria, www.vwr.com). 3'-methyl-4-hydroxyacetophenone, 4'-butoxyacetophenone and 2-fluoro-4-hydroxyacetophenone were from TCI Europe (www.tcichemicals.com). Poly(ethylene terephthalate) (PET) support Melinex 505 was obtained from Pütz (Germany, www.puetz-folien.com). Potassium chloride, potassium carbonate (pro analysi), potassium hydroxide and silica gel $60(0.063-0.200 \mathrm{~mm})$ were received from Merck (www.merck.at). Sodium hydroxide, ethyl acetate, the buffer salts CHES, MES and CAPS were purchased from Roth (www.carlroth.com). De-ionized water was filtered via a Barnstead NANOpure ultrapure water system. 1-(4-Hydroxyphenyl)-4-nitro-3-phenylbutan-1-one (compound 1b) was synthesized according to Jokic et al. ${ }^{38}$ Silanized Egyptian blue particles were prepared according to the literature procedure. ${ }^{46}$

Synthesis of 3,7-bis(4-butoxyphenyl)-5,5-difluoro-1,9-diphenyl$5 H-4 \lambda^{4}, 5 \lambda^{4}$-dipyrrolo[1,2-c:2' $\left.{ }^{\prime} 1^{\prime}-f\right][1,3,5,2]$ triazaborinine (di-butoxycomplex)

(E)-1-(4-Butoxyphenyl)-3-phenylprop-2-en-1-one (compound a). 4 '-Butoxyacetophenone (1 eq., $2.00 \mathrm{~g}, 15.5 \mathrm{mmol}$ ) was dissolved in absolute ethanol $(15 \mathrm{ml})$. Benzaldehyde (1 eq., $1580 \mu \mathrm{l}$, $15.5 \mathrm{mmol}$ ) and potassium hydroxide (3 eq., $2.61 \mathrm{~g}, 46.4 \mathrm{mmol}$ in $5 \mathrm{ml} \mathrm{H}_{2} \mathrm{O}$ ) were added to the solution and the reaction was stirred at room temperature for $12 \mathrm{~h}$. Then, the reaction solution/suspension was acidified with $0.1 \mathrm{M} \mathrm{HCl}$ and the resulting precipitate was collected by filtration and was washed with water three times $(3 \times 100 \mathrm{ml})$. The precipitate was dried on a rotary evaporator and was used for the next step without further purification $(3.87 \mathrm{~g}, 89.2 \%)$.

1-(4-Butoxyphenyl)-4-nitro-3-phenylbutan-1-one (compound b). A solution of (E)-1-(4-butoxyphenyl)-3-phenylprop-2-en-1-one (1 eq., $3.87 \mathrm{~g}, 13.8 \mathrm{mmol}$ ), nitromethane (20 eq., $14.8 \mathrm{ml}$, $276 \mathrm{mmol}$ ) and $\mathrm{KOH}(0.3 \mathrm{eq} ., 0.232 \mathrm{~g}, 4.1 \mathrm{mmol})$ in $30 \mathrm{ml}$ of absolute ethanol was heated under reflux for $12 \mathrm{~h}$. After cooling to room temperature the solvent was removed on a rotary evaporator. The resulting oily residue was acidified with $0.1 \mathrm{M} \mathrm{HCl}$ and was partitioned with ethyl acetate and water in a separating funnel. The organic layer was separated, dried over sodium sulfate and the solvent was removed under reduced pressure $(4.035 \mathrm{~g}, 85.7 \%)$.

(5Z)-5-(4-Butoxyphenyl)-N-(5-(4-butoxyphenyl)-3-phenyl-2H-pyrrol2-ylidene)-3-phenyl-1H-pyrrol-2-amine (c). Compound b (1 eq., $2.5 \mathrm{~g}, 7.33 \mathrm{mmol}$ ) and ammonium acetate (35 eq., $19.77 \mathrm{~g}$, $256 \mathrm{mmol}$ ) were dissolved in $50 \mathrm{ml}$ of 1-butanol and the reaction solution was heated under reflux for $24 \mathrm{~h}$. The reaction was cooled to room temperature and the solvent was removed under reduced pressure. Then, the solid was redissolved in DCM and washed with water three times $(3 \times 100 \mathrm{ml})$. The crude solid was purified by column chromatography on silica gel, eluting with DCM/cyclohexane $(1: 1 \mathrm{v} / \mathrm{v})$. The product was recrystallized from a hexane-THF mixture to give metallic blue crystals (983 mg, 45.4\%). ${ }^{1} \mathrm{H}$ NMR (300 $\mathrm{MHz}, \mathrm{CDCl}_{3}$ ) $\delta 8.06(\mathrm{~d}, J=7.1 \mathrm{~Hz}, 4 \mathrm{H}), 7.88-7.83(\mathrm{~m}, 4 \mathrm{H}), 7.44-7.31(\mathrm{~m}, 6 \mathrm{H})$, $7.11(\mathrm{~s}, 2 \mathrm{H}), 7.02(\mathrm{~d}, J=8.8 \mathrm{~Hz}, 4 \mathrm{H}), 4.06(\mathrm{t}, J=6.5 \mathrm{~Hz}, 4 \mathrm{H})$, 1.91-1.72 (q, $J=8.5 \mathrm{~Hz}, 4 \mathrm{H}), 1.6-1.48(\mathrm{~m}, 4 \mathrm{H}), 1.01(\mathrm{t}, J=$ $7.4 \mathrm{~Hz}, 6 \mathrm{H})$.

3,7-Bis(4-butoxyphenyl)-5,5-difluoro-1,9-diphenyl-5H-4 $\lambda^{4}, 5 \lambda^{4}$ dipyrrolo[1,2-c:2', $\left.1^{\prime}-f\right][1,3,5,2]$ triazaborinine. Compound $\mathbf{c}$ (1 eq., $300 \mathrm{mg}, 0.51 \mathrm{mmol}$ ) was dissolved in $200 \mathrm{ml}$ of dry DCM. $N, N$ Diisopropylethylamine (DIPEA, 10 eq., $839 \mu \mathrm{l}, 5.06 \mathrm{mmol}$ ) and boron trifluoride diethyl etherate (15 eq., $953 \mu \mathrm{l}, 7.58 \mathrm{mmol}$ ) were added and the reaction solution was stirred under nitrogen for $12 \mathrm{~h}$. The green solution was washed with water three times $(3 \times 200 \mathrm{ml})$ and dried over anhydrous sodium sulfate. The crude product was purified by column chromatography on silica gel, eluting with DCM/cyclohexane $(1: 1 \mathrm{v} / \mathrm{v})$. The product was recrystallized from a hexane-THF mixture to give metallic red needles (179 mg, 55.2\%). ${ }^{1} \mathrm{H}$ NMR $\left(300 \mathrm{MHz}, \mathrm{CDCl}_{3}\right) \delta 8.09-$ $8.05(\mathrm{~m}, 8 \mathrm{H}), 7.49-7.38(\mathrm{~m}, 6 \mathrm{H}), 7.04-6.98(\mathrm{~m}, 6 \mathrm{H}), 4.07-4.02$ $(\mathrm{t}, J=6.4 \mathrm{~Hz}, 4 \mathrm{H}), 1.58-1.45(\mathrm{q}, J=14.4 \mathrm{~Hz}, 4 \mathrm{H}), 1.62-1.42$ $(\mathrm{m}, 4 \mathrm{H}), 1.02-0.97(\mathrm{t}, J=7.4 \mathrm{~Hz}, 6 \mathrm{H})$. Electron impact-direct insertion-time of flight (DI-EI-TOF): $\mathrm{m} / z$ of $[\mathbf{M}]^{+}$was found to be 641.3007, calc. 641.3032.

Synthesis of $4,4^{\prime}$-(5,5-difluoro-1,9-diphenyl-5H-4$\lambda^{4}, 5 \lambda^{4}$-dipyrrolo$\left[1,2-c: 2^{\prime}, 1^{\prime}-f\right][1,3,5,2]$ triazaborinine-3,7-diyl)bis(2-chlorophenol) (di-Cl-di-OH-complex)

1-(3-Chloro-4-hydroxyphenyl)-3-phenylpropenone (compound 1a). 3'-Chloro-4'-hydroxyacetophenone (1 eq., 2 g, $11.7 \mathrm{mmol}$ ) and 
benzaldehyde ( 1 eq., $1.24 \mathrm{~g}, 11.7 \mathrm{mmol}$ ) were dissolved in $10 \mathrm{ml}$ of ethanol absolute. $10 \mathrm{ml}$ of aqueous potassium hydroxide solution (3 eq., $1.96 \mathrm{~g}, 35.1 \mathrm{mmol}$ ) were added dropwise. The resulting solution was stirred for $8-12 \mathrm{~h}$, during which the product precipitated as a potassium salt. The solution/suspension was poured into $10 \mathrm{ml}$ of hydrochloric acid (1 M) and further concentrated hydrochloric acid was added until the solution became acidic. The obtained yellow solid was washed with water and used for further synthesis without purification (2.33 g, 77\%).

1-(3-Chloro-4-hydroxyphenyl)-4-nitro-3-phenylbutan-1-one (compound 1b). A solution of compound 1a (1 eq., $2 \mathrm{~g}$, $7.7 \mathrm{mmol}$ ), nitromethane (20 eq., $8.35 \mathrm{ml}, 154.7 \mathrm{mmol}$ ) and potassium hydroxide (1.2 eq., $0.52 \mathrm{~g}, 9.28 \mathrm{mmol}$ ) in $10 \mathrm{ml}$ of ethanol was heated at $60{ }^{\circ} \mathrm{C}$ under reflux for $12 \mathrm{~h}$. After cooling to room temperature, the solvent was removed in vacuo and the oily residue obtained was acidified with hydrochloric acid (4 M) and partitioned between ethyl acetate $(50 \mathrm{ml})$ and de-ionized water $(50 \mathrm{ml})$. The organic layer was separated, dried over anhydrous sodium sulfate and evaporated under reduced pressure. The obtained product was used for further synthesis without purification $(2.4 \mathrm{~g}, 97.2 \%)$.

[5-(3-Chloro-4-hydroxyphenyl)-3-phenyl-1H-pyrrol-2-yl]-[5-(3-chloro4-hydroxyphenyl)-3-phenylpyrrol-2-ylidene]amine (compound 1c). Compound 1b (1 eq., $2.02 \mathrm{~g}, 8.76 \mathrm{mmol}$ ) and ammonium acetate (35 eq., $19.03 \mathrm{~g}, 307 \mathrm{mmol}$ ) in $50 \mathrm{ml}$ of 1-butanol were heated under reflux for $24 \mathrm{~h}$. The reaction was cooled to room temperature, the salt was removed by extraction with de-ionized water/DCM and the product was purified by column chromatography on silica gel, eluting with 5\% ethyl acetate/DCM (after eluting impurities with hexane, 20\% DCM/hexane, 1\% ethyl acetate/DCM and 2\% ethyl acetate/DCM) to yield 1c as a blueblack solid. The product was recrystallized from a hexane-THF mixture to give metallic green crystals $(0.097 \mathrm{~g}, 5.77 \%) .{ }^{1} \mathrm{H}$ NMR $\left(300 \mathrm{MHz}\right.$, DMSO- $\left.d_{6}\right) \delta 8.09(\mathrm{~d}, J=7.6 \mathrm{~Hz}, 6 \mathrm{H}), 7.90(\mathrm{~d}, J=$ $8.5 \mathrm{~Hz}, 2 \mathrm{H}), 7.62(\mathrm{~s}, 2 \mathrm{H}), 7.54-7.32(\mathrm{~m}, 6 \mathrm{H}), 7.19(\mathrm{~d}, J=8.5 \mathrm{~Hz}$, 2H). EI-DI-TOF: $m / z[\mathrm{MH}]^{+}$found 549.1007, calc. 549.1011.

4,4'-(5,5-Difluoro-1,9-diphenyl-5H-4 $\lambda^{4}, 5 \lambda^{4}$-dipyrrolo[1,2-c: $\left.2^{\prime}, 1^{\prime}-f\right]$ [1,3,5,2]triazaborinine-3,7-diyl)bis(2-chlorophenol) (di-Cl-di-OHcomplex). Compound 1c $(0.017 \mathrm{~g}, 0.07 \mathrm{mmol})$ was dissolved in $50 \mathrm{ml}$ of dry DCM, treated with DIPEA (10 eq., $0.053 \mathrm{ml}$, $0.32 \mathrm{mmol}$ ) and boron trifluoride diethyletherate (15 eq., $0.061 \mathrm{ml}, 0.48 \mathrm{mmol}$ ) and stirred under argon for $24 \mathrm{~h}$. Purification was carried out via column chromatography on silica gel, eluting with $2 \%$ ethanol/DCM (after eluting impurities with DCM). Recrystallization from hexane-THF gave the final product di-Cl-di-OH-complex as a metallic red solid $(0.008 \mathrm{~g}, 44 \%)$. ${ }^{1} \mathrm{H}$ NMR (300 MHz, DMSO- $\left.d_{6}\right) \delta 8.29(\mathrm{~s}, 2 \mathrm{H}), 8.16$ (d, $J=7.0 \mathrm{~Hz}$, $4 \mathrm{H}), 8.03(\mathrm{~d}, J=8.7 \mathrm{~Hz}, 2 \mathrm{H}), 7.65(\mathrm{~s}, 2 \mathrm{H}), 7.60-7.41(\mathrm{~m}, 6 \mathrm{H})$, $7.13(\mathrm{~d}, J=8.7 \mathrm{~Hz}, 2 \mathrm{H})$. EI-DI-TOF: $m / z[\mathrm{MH}]^{+}$found 597.0968, calc. 597.0999 .

Synthesis of $4,4^{\prime}$-(5,5-difluoro-1,9-diphenyl-5H-4$\lambda^{4}, 5 \lambda^{4}$-dipyrrolo$\left[1,2-c: 2^{\prime}, 1^{\prime}-f\right][1,3,5,2]$ triazaborinine-3,7-diyl)bis(3-fluorophenol) (di-F-di-OH-complex). The synthesis was performed analogously to that of the di-Cl-di-OH-complex, but starting from 2'-fluoro-4'-hydroxyacetophenone (728 mg). Steps 1 and 2 yielded $1.033 \mathrm{~g}(90.2 \%)$ and $1.28 \mathrm{~g}(99.4 \%)$ of the crude product, respectively. After synthesis step 3, the crude product was purified by column chromatography on silica gel, eluting with 4\% THF/DCM to yield [5-(2-fluoro-4-hydroxyphenyl)-3-phenyl1H-pyrrol-2-yl]-[5-(2-fluoro-4-hydroxyphenyl)-3-phenylpyrrol-2ylidene]amine 2c as a blue-black solid. The product was recrystallized from a hexane-THF mixture to give metallic green crystals $(0.23 \mathrm{~g}, 20.9 \%) .{ }^{1} \mathrm{H}$ NMR $\left(300 \mathrm{MHz}\right.$, DMSO- $\left.d_{6}\right) \delta 8.04-$ $8.06(\mathrm{~d}, J=7.0 \mathrm{~Hz}, 6 \mathrm{H}), 7.35-7.47(\mathrm{~m}, 8 \mathrm{H}), 6.78-6.86(\mathrm{~m}, 4 \mathrm{H})$. DI-EI-TOF: $m / z$ of $[\mathrm{M}]^{+}$found 517.1626, calc. 517.1602.

4,4'-(5,5-Difluoro-1,9-diphenyl-5H-4 $\lambda^{4}, 5 \lambda^{4}$-dipyrrolo[1,2-c: $\left.2^{\prime}, 1^{\prime}-f\right]$ [1,3,5,2]triazaborinine-3,7-diyl)bis(3-fluorophenol) (di-F-di-OH-complex). 4,4'-(5,5-Difluoro-1,9-diphenyl-5 $H$ - $4 \lambda^{4}, 5 \lambda^{4}$-dipyrrolo[1,2-c: $\left.2^{\prime}, 1^{\prime}-f\right]$ $[1,3,5,2]$ triazaborinine-3,7-diyl)bis(3-fluorophenol) (di-F-di-OHcomplex) was synthesized using the same procedure. Purification was carried out via column chromatography on silica gel, eluting with $4 \%$ THF/DCM. Recrystallization from hexane-THF gave the final product di-F-di-OH-complex as a metallic red solid $(0.044 \mathrm{~g}, 19.6 \%) .{ }^{1} \mathrm{H}$ NMR $\left(300 \mathrm{MHz}\right.$, DMSO- $\left.d_{6}\right) \delta 8.12(\mathrm{~d}, J=$ $7.0 \mathrm{~Hz}, 4 \mathrm{H}), 7.82(\mathrm{t}, J=8.7 \mathrm{~Hz}, 2 \mathrm{H}), 7.56-7.48(\mathrm{q}, J=9.4,7.9 \mathrm{~Hz}$, $6 \mathrm{H}), 7.31$ (d, $J=3.4 \mathrm{~Hz}, 2 \mathrm{H}), 6.77$ (d, $J=10.7 \mathrm{~Hz}, 4 \mathrm{H})$. DI-EI-TOF: $\mathrm{m} / \mathrm{z}$ of $[\mathrm{M}]^{+}$found 565.1615 , calc. 565.1591.

Synthesis of $4,4^{\prime}$-(5,5-difluoro-1,9-diphenyl-5H-4 $\lambda^{4}, 5 \lambda^{4}$-dipyrrolo$\left[1,2-c: 2^{\prime}, 1^{\prime}-f\right][1,3,5,2]$ triazaborinine-3,7-diyl)diphenol (di-OHcomplex). Compound 3a 1-(4-hydroxyphenyl)-3-phenylpropenone was commercially available. Further synthesis steps were performed analogously to the synthesis steps of the di-Cl-di-OHcomplex. The synthesis of compound $3 \mathbf{b}$ gave $2.06 \mathrm{~g}(80 \%)$ of the crude product, starting from $2.02 \mathrm{~g}$ of $4^{\prime}$-hydroxychalcone. The crude 3c was purified by column chromatography on silica gel, eluting with 4\% THF/DCM to yield [5-(4-hydroxyphenyl)-3phenyl-1 $H$-pyrrol-2-yl]-[5-(4-hydroxyphenyl)-3-phenylpyrrol-2-ylidene]amine as a blue-black solid. The product was recrystallized from a hexane-THF mixture to give metallic green crystals $(0.41 \mathrm{~g}$, 23.5\%). ${ }^{1} \mathrm{H}$ NMR (300 MHz, DMSO- $\left.d_{6}\right), \delta 8.09$ (d, $\left.J=7.3 \mathrm{~Hz}, 4 \mathrm{H}\right)$, $7.93(\mathrm{~d}, J=8.6 \mathrm{~Hz}, 4 \mathrm{H}), 7.53(\mathrm{~s}, 2 \mathrm{H}), 7.42(\mathrm{~m}, 6 \mathrm{H}), 7.01(\mathrm{~d}, J=$ $8.6 \mathrm{~Hz}, 4 \mathrm{H})$. EI-DI-TOF: $m / z[\mathrm{MH}]^{+}$found 481.1773 , calc. 481.179 .

Purification of 4,4'-(5,5-difluoro-1,9-diphenyl-5H-4 $\lambda^{4}, 5 \lambda^{4}$-dipyrrolo$\left[1,2-c: 2^{\prime}, 1^{\prime}-f\right][1,3,5,2]$ triazaborinine-3,7-diyl)diphenol. Purification of $4,4^{\prime}$-(5,5-difluoro-1,9-diphenyl-5 $H$ - $4 \lambda^{4}, 5 \lambda^{4}$-dipyrrolo[1,2-c: $\left.2^{\prime}, 1^{\prime}-f\right]$ $[1,3,5,2]$ triazaborinine-3,7-diyl)diphenol was carried out via column chromatography on silica gel, eluting with DCM/ethyl acetate $(4: 1)$. Recrystallization from hexane-THF gave the final product di-OH-complex as a metallic red solid $(0.26 \mathrm{~g}, 57.8 \%)$. ${ }^{1} \mathrm{H}$ NMR (300 MHz, DMSO- $\left.d_{6}\right) \delta 8.13(\mathrm{dd}, J=18.6,8.0 \mathrm{~Hz}, 8 \mathrm{H})$, $7.65-7.39(\mathrm{~m}, 8 \mathrm{H}), 6.95(\mathrm{~d}, J=8.8 \mathrm{~Hz}, 4 \mathrm{H})$. EI-DI-TOF: $m / z[\mathrm{MH}]^{+}$ found 529.1771 , calc. 529.1779 .

Synthesis of the $4,4^{\prime}-\left(5,5\right.$-difluoro-1,9-diphenyl-5H-4 $\lambda^{4}$, $5 \lambda^{4}$-dipyrrolo[1,2-c:2 $\left.2^{\prime}, 1^{\prime}-f\right][1,3,5,2]$ triazaborinine-3,7-diyl)bis(2-methylphenol) (di- $\mathrm{CH}_{3}$-di-OH-complex). The synthesis was carried out analogously to that of the di-Cl-di-OH-complex, starting from 3 '-methyl-4'-hydroxyacetophenone $(1.88 \mathrm{~g})$. Steps 1 and 2 yielded $2.77 \mathrm{~g}$ (93\%) and $1.84 \mathrm{~g}$ (53\%) of the crude 
product, respectively. After synthesis step 3, the crude product was purified by column chromatography on silica gel, eluting with 5\% ethyl acetate/DCM (after eluting impurities with hexane/DCM 1:1, DCM) to yield [5-(3-methyl-4-hydroxyphenyl)-3phenyl-1H-pyrrol-2-yl]-[5-(3-methyl-4-hydroxyphenyl)-3-phenylpyrrol2-ylidene]amine $\mathbf{4 c}$ as a blue-black solid. The product was recrystallized from a hexane-THF mixture to give metallic green crystals (0.091 g, 5.8\%). ${ }^{1} \mathrm{H}$ NMR (300 MHz, DMSO- $\left.d_{6}\right) \delta 8.10$ (d, $J=7.3 \mathrm{~Hz}, 4 \mathrm{H}), 7.91-7.75(\mathrm{~m}, 4 \mathrm{H}), 7.57-7.33(\mathrm{~m}, 8 \mathrm{H}), 7.00$ (d, $J=8.4 \mathrm{~Hz}, 2 \mathrm{H}), 2.29$ (s, 6H). EI-DI-TOF: $m / z[\mathrm{MH}]^{+}$found 509.2086, calc. 509.2103.

Purification of 4,4'-(5,5-difluoro-1,9-diphenyl-5H-4 $\lambda^{4}, 5 \lambda^{4}$-dipyrrolo[1,2-c:2' $\left.1^{\prime}-f\right][1,3,5,2]$ triazaborinine-3,7-diyl)bis(2-methylphenol). Purification of $4,4^{\prime}$-(5,5-difluoro-1,9-diphenyl-5 $H$ - $4 \lambda^{4}, 5 \lambda^{4}$-dipyrrolo$\left[1,2-c: 2^{\prime}, 1^{\prime}-f\right][1,3,5,2]$ triazaborinine-3,7-diyl)bis(2-methylphenol) was carried out via column chromatography on silica gel, eluting with $5 \%$ ethyl acetate/DCM (after eluting impurities with DCM, 1\% ethyl acetate/DCM and $2 \%$ ethyl acetate/DCM). Recrystallization from hexane-THF gave the final product di- $\mathrm{CH}_{3}$ di-OH-complex as a metallic red solid (0.04 g, 40\%). ${ }^{1} \mathrm{H}$ NMR $\left(300 \mathrm{MHz}\right.$, DMSO- $\left.d_{6}\right) \delta 8.16(\mathrm{~d}, J=7.2 \mathrm{~Hz}, 4 \mathrm{H}), 8.08-7.90$ $(\mathrm{m}, 4 \mathrm{H}), 7.52(\mathrm{~m}, 8 \mathrm{H}), 6.95(\mathrm{~d}, J=8.5 \mathrm{~Hz}, 2 \mathrm{H}), 2.22(\mathrm{~s}, 6 \mathrm{H})$. EI-DI-TOF: $m / z[\mathrm{MH}]^{+}$found 557.2082, calc. 557.2092.

\section{Staining of PS-microparticles}

$0.50 \mathrm{~g}$ of PS-particles were dispersed in a solution of $5 \mathrm{mg}$ of $(1 \% \mathrm{w} / \mathrm{w}$ in respect to the PS-particles) the di-butoxy-complex in $10 \mathrm{ml}$ of tetrahydrofuran (THF) and stirred for $1.5 \mathrm{~h}$. Then $8 \mathrm{ml}$ of de-ionized water were added dropwise. After $10 \mathrm{~min}$ of stirring the dispersion was transferred rapidly into a beaker with $50 \mathrm{ml}$ of de-ionized water. The dispersion was again stirred for $10 \mathrm{~min}$. Then the particles were filtered through a cellulose filter and rewashed with $20 \mathrm{ml}$ of ethanol. Afterwards the particles were transferred into a milling cup and were overlaid with a mixture of ethanol/de-ionized water $(1: 1)$ to reduce friction and to enhance heat dissipation during grinding in the planet mill. The particles were washed with ethanol and dried in the oven at $70{ }^{\circ} \mathrm{C}$.

\section{Sensor preparation}

Absorption: a "cocktail" containing $100 \mathrm{mg}$ of ethyl cellulose and $1 \mathrm{mg}$ of dye (1\% w/w with respect to the polymer) dissolved in a toluene : ethanol mixture $(6: 4 \mathrm{v} / \mathrm{v}, 1.9 \mathrm{~g})$ was purged with carbon dioxide. Afterwards $100 \mu \mathrm{l}$ of tetraoctylammonium hydroxide solution $(20 \% \mathrm{w} / \mathrm{w}$ TOAOH in $\mathrm{MeOH})$ were added. The "cocktail" was knife-coated on a dust-free PET support. A sensing film of $\sim 7 \mu \mathrm{m}$ thickness was obtained after evaporation of the solvent. For luminescence-based measurements a second layer was added to the absorption-based sensing foils. To prepare the "cocktail" for the second layer, $0.180 \mathrm{~g}$ of Hyflon $\mathrm{AD} 60$ were dissolved in $2.820 \mathrm{~g}$ of perfluorodecalin, which was washed prior to use with $1 \mathrm{~mol} \mathrm{l}^{-1}$ potassium carbonate solution. Then $0.360 \mathrm{~g}$ of Egyptian blue powder $(200 \% \mathrm{w} / \mathrm{w}$ with respect to the polymer) and $0.054 \mathrm{~g}$ of stained PS-particles $(30 \% \mathrm{w} / \mathrm{w}$ with respect to the polymer) were dispersed homogeneously in the Hyflon solution. The thickness of this layer after evaporation of the solvent was estimated to be $\sim 4.5 \mu \mathrm{m}$.

\section{Methods}

${ }^{1} \mathrm{H}$ NMR spectra were recorded on a $300 \mathrm{MHz}$ instrument (Bruker) in DMSO- $d_{6}$ with TMS as standard. Absorption spectra were recorded on a Cary $50 \mathrm{UV}$-Vis spectrophotometer (Varian). The determination of the molar absorption coefficients was carried out as an average of three independent measurements. Fluorescence spectra were recorded on a Fluorolog3 fluorescence spectrometer (Horiba) equipped with a NIR-sensitive photomultiplier R2658 from Hamamatsu (300-1050 nm). Photobleaching experiments were performed by irradiating the sensor foils in a glass cuvette with the light of a highpower $10 \mathrm{~W}$ LED array $\left(\lambda_{\max } 458 \mathrm{~nm}, 3\right.$ LEDs, www.LED-TECH. de) operated at $6 \mathrm{~W}$ input power. A lens (Edmund Optics) was used to focus the light of the LED array on the glass cuvette (photon flux: $\sim 3900 \mu \mathrm{mol} \mathrm{s} \mathrm{s}^{-1} \mathrm{~m}^{-2}$ as determined using a Li-250A light meter from Li-COR). The photodegradation profiles were obtained by monitoring the absorption spectra of a sensor foil based on the respective dye. The cuvette was flushed with either carbon dioxide gas for the mono-anionic form, or with nitrogen for the di-anionic form and sealed. Thymol-blue and $m$-cresol-purple were used for comparison. In the case of the anionic form of thymol-blue, $m$-cresol-purple, the di-OHcomplex and the di- $\mathrm{CH}_{3}$-di-OH-complex (di-anionic forms) sodium hydroxide was placed at the bottom of the cuvette to capture carbon dioxide traces. Gas calibration mixtures were obtained using a gas mixing device from MKS (www.mksinst.com). The gas mixture was humidified to about $85 \%$ relative humidity, using silica gel soaked with a saturated potassium chloride solution, prior to entering the calibration chamber. Temperature was controlled by a cryostat ThermoHaake DC50. Dyed particles were filtered through cellulose filters type 113A from Roth (www.carlroth.com). Particle milling was carried out using an $80 \mathrm{ml}$ milling cup, zirconia spheres $(\varnothing 5 \mathrm{~mm})$ and a Pulverisette 6 planet mill from Fritsch (www.fritsch.de). For the determination of the $\mathrm{p} K_{\mathrm{a}}$ values titration curves in aqueous buffer/ethanol mixtures $(1: 1)$ were measured and the average value of the point of inflection obtained was used. For the production/consumption measurements of carbon dioxide two Firesting-Mini devices and an oxygen trace sensor from PyroScience (www.pyro-science.com) were used. Illumination of the sample was performed using 3 commercially available halogen bulb lamps with an averaged photon flux of $\sim 217 \mu \mathrm{mol} \mathrm{s}^{-1} \mathrm{~m}^{-2}$ per lamp. The plant was positioned in a glass desiccator, which was flushed with a gas mixture of $2 \%$ oxygen in nitrogen.

\section{Results and discussion}

\section{Synthesis}

As reported by Jokic et al. ${ }^{38}$ there are two ways for the preparation of azadipyrromethenes to obtain either asymmetrical ${ }^{47}$ or symmetrical ${ }^{48}$ chromophores. The previously published 
asymmetrical dyes bearing one hydroxyl group were proved to be promising $\mathrm{pH}$ indicators. ${ }^{38}$ Unfortunately, they were found to be unsuitable for optical carbon dioxide sensors. The ion pair built between the hydroxyl group and the tetraoctylammonium base was comparatively strong. Even after exposure of the sensors to pure carbon dioxide, the amount of $\mathrm{CO}_{2}$ was not enough to achieve re-protonation of the indicators and only after exposure to strong acid vapors (e.g. hydrochloric acid) the indicators were irreversibly re-protonatable.

Dissociation of both hydroxyl groups in symmetrical azadipyrromethenes was expected to be more difficult compared to the mono-hydroxy derivatives since two ion pairs with bulky cations would be built upon deprotonation. Therefore, this new class of $\mathrm{pH}$ indicators potentially suitable for $\mathrm{CO}_{2}$ sensing was investigated. The starting point of our synthesis was diaryl$\alpha, \beta$-unsaturated ketones (chalcones) either commercially available or readily made by an aldol condensation of the corresponding aldehyde and acetophenone (Scheme 1). The Michael addition of nitromethane to the chalcones, using $\mathrm{KOH}$ as a base, yields 1,3-diaryl-4-nitrobutan-1-ones in essentially quantitative yields. Their condensation with ammonium acetate in refluxing butanol gave azadipyrromethenes. Finally, the azadipyrromethenes were
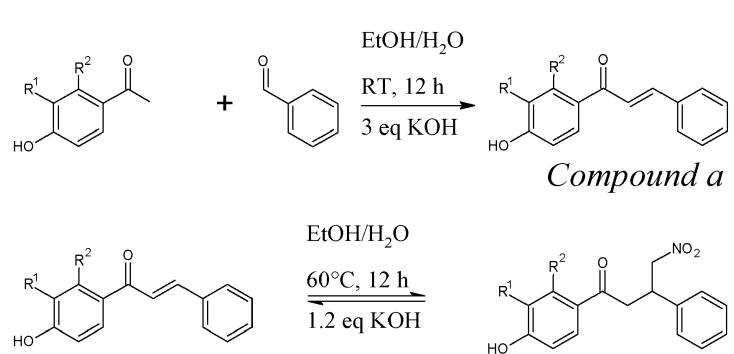

$\mathrm{EtOH} / \mathrm{H}_{2} \mathrm{O}$
$\frac{60^{\circ} \mathrm{C}, 12 \mathrm{~h}}{1.2 \mathrm{eq} \mathrm{KOH}}$

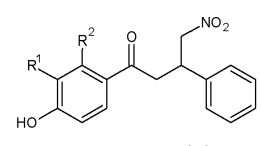

Compound b
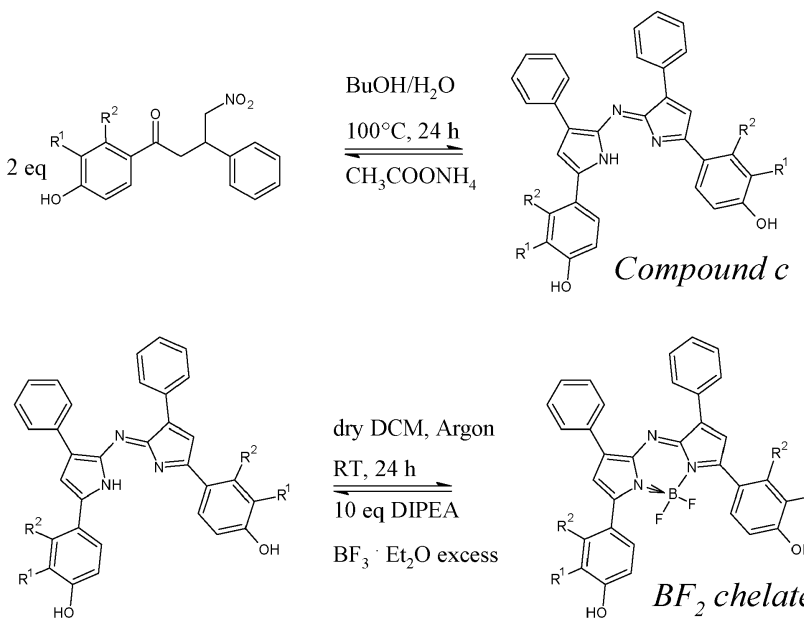

dry DCM, Argon

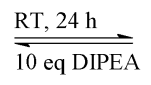

$\mathrm{BF}_{3} \cdot \mathrm{Et}_{2} \mathrm{O}$ excess

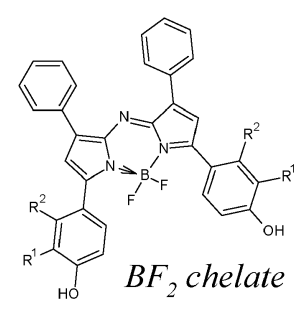

\footnotetext{
di-OH-complex: $\mathrm{R}^{1}=\mathrm{R}^{2}=\mathrm{H}$

di-F-di-OH-complex: $\mathrm{R}^{1}=\mathrm{H}, \mathrm{R}^{2}=\mathrm{F}$

di-Cl-di-OH-complex: $\mathrm{R}^{1}=\mathrm{Cl}, \mathrm{R}^{2}=\mathrm{H}$

di-CH $\mathrm{CH}_{3}$-di-OH-complex: $\mathrm{R}^{1}=\mathrm{CH}_{3}, \mathrm{R}^{2}=\mathrm{H}$
}

Scheme 1 4-Step-synthesis of the di-OH-aza-BODIPY chelates.
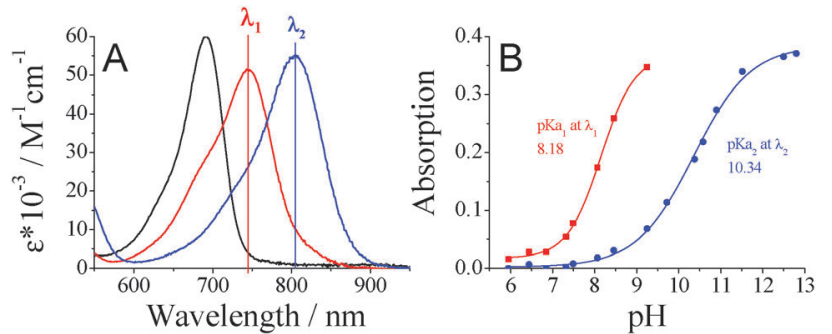

Fig. 1 (A) Absorption spectra of the neutral (black line, $\mathrm{pH}$ 6.4), the monoanionic (red line, $\mathrm{pH}$ 9.3) and the di-anionic (blue line, $\mathrm{pH}$ 12.8) forms of the di-OH-complex dissolved in the ethanol/aqueous buffer mixture (1:1) at $25^{\circ} \mathrm{C}$ and (B) the titration curves for $\mathrm{p} K_{\mathrm{a} 1}$ determined at $745 \mathrm{~nm}$ (red) and $\mathrm{p} K_{\mathrm{a} 2}$ at $805 \mathrm{~nm}$ (blue), respectively.

converted to the corresponding $\mathrm{BF}_{2}$ chelates via reaction with $\mathrm{BF}_{2}$-etherate using diisopropylethylamine as a base at room temperature for $24 \mathrm{~h}$, giving yields ranging from 20 to $70 \%$.

\section{Photophysical properties}

Dissolved in an ethanol/aqueous buffer mixture (1:1) all di-OHaza-BODIPY dyes showed absorption spectra corresponding to the two protonation steps of the hydroxyl groups (Fig. 1). The neutral forms showed maxima at $670-700 \mathrm{~nm}$ and the monoanionic forms at 725-760 $\mathrm{nm}$. The di-anionic forms were again bathochromically shifted for approximately $60 \mathrm{~nm}\left(\lambda_{\max } 785-\right.$ $830 \mathrm{~nm})$. Generally, the di- $\mathrm{CH}_{3}$-di-OH-complex bearing electrondonating methyl groups showed absorption maxima shifted to higher wavelengths compared to the non-substituted di-OHcomplex (Table 1). In contrast, complexes bearing electronwithdrawing groups displayed absorption maxima at shorter wavelengths.

An overview of the spectroscopic properties of the presented dyes is given in Table 1. Molar absorption coefficients are rather high: $55000-77000 \mathrm{M}^{-1} \mathrm{~cm}^{-1} \cdot \mathrm{p} K_{\mathrm{a}}$ determination was carried out in a mixture of ethanol/aqueous buffer solution $(1: 1)$. For all di-OH-aza-BODIPY dyes two protonation steps can be observed (Table 1). Here, the complex with electron-donating methyl groups in the ortho-position to the hydroxyl groups showed the highest $\mathrm{p} K_{\mathrm{a}}$ values, followed by the non-substituted di-OH-complex. Electron-withdrawing chlorine atoms located in the proximity of the hydroxyl groups (ortho-position) have the strongest impact on the $\mathrm{p} K_{\mathrm{a}}$ values, whereas the electronwithdrawing effect of fluorine atoms in the meta-position is significantly lower.

\section{Carbon dioxide sensors}

The $\mathrm{pH}$-sensitive di-OH-aza-BODIPY dyes were embedded in an ethyl cellulose matrix (EC49) along with tetraoctylammonium hydroxide as a base to obtain optical carbon dioxide sensors. Clearly, the sensors showed well-observable spectral changes in the near infrared (NIR) range according to the protonation of the di-anionic form giving the mono-anionic form (Fig. 2). The neutral forms of the di-OH-complexes showed slight fluorescence in solution, and the sensors based on the indicators did not show detectable fluorescence, neither for the mono-anionic 


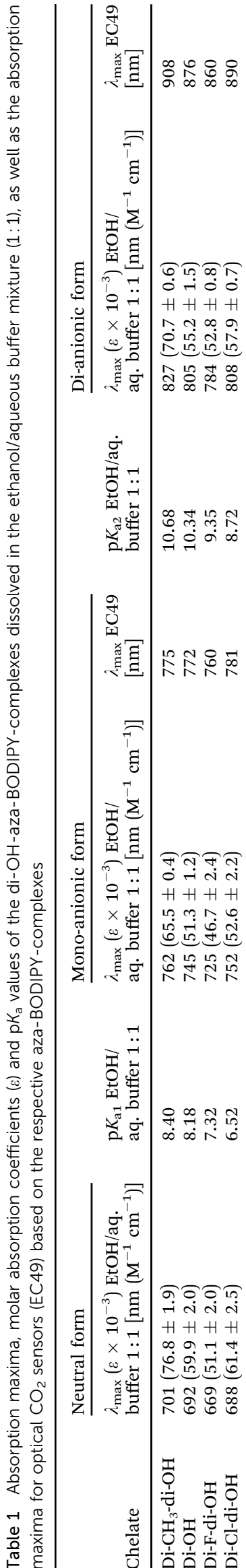

nor for the di-anionic form. Compared to the measurements in solution the $\mathrm{CO}_{2}$ sensors based on the di-OH-aza-BODIPY dyes showed significantly bathochromically shifted absorption spectra with maxima at 760-780 $\mathrm{nm}$ for their mono-anionic forms and maxima at 860-910 $\mathrm{nm}$ for their di-anionic forms. Generally, a similar trend for the absorption maxima of the $\mathrm{CO}_{2}$ sensors based on the respective complexes was observed (Table 1). Here, the shift between the mono-anionic and the di-anionic form was enlarged to over $100 \mathrm{~nm}$. This fact is advantageous for optical sensors, because peak separation becomes easier.

Despite the fact that all di-OH-aza-BODIPY dyes showed two protonation steps in aqueous solution, only one protonation step was observed in optical sensors based on these indicators. In fact, in the absence of carbon dioxide both hydroxyl groups build ion pairs with the quaternary ammonium base and the spectra of the di-anionic forms are observable. The monoanionic form is built in the presence of carbon dioxide and is stable even at $100 \% \mathrm{CO}_{2}$. Spectra of the neutral forms are not observable anymore (Fig. 2). Therefore, the $\mathrm{p} K_{\mathrm{a} 2}$ values measured in solution are most relevant for optical carbon dioxide sensors based on the di-OH-aza-BODIPY dyes. Indeed, these values correlate very well with the sensitivities of the optical $\mathrm{CO}_{2}$ sensors (Table 1 and Fig. 3). The sensitivity increases in the following order: di-Cl-di-OH $<$ di-F-di-OH $<$ di-OH $<$ di- $\mathrm{CH}_{3}$ di-OH. Notably, for the most sensitive sensor based on di- $\mathrm{CH}_{3}-$ di-OH about $25 \%$ of the overall signal change is observed already at atmospheric $p \mathrm{CO}_{2}$ which is, to the best of our knowledge, one of the highest sensitivities reported so far. Di-F-di-OH and di-Cl-di-OH complexes bearing electron-withdrawing groups displayed diminished $\mathrm{p} K_{\mathrm{a} 2}$ values of 9.35 and 8.72, respectively,
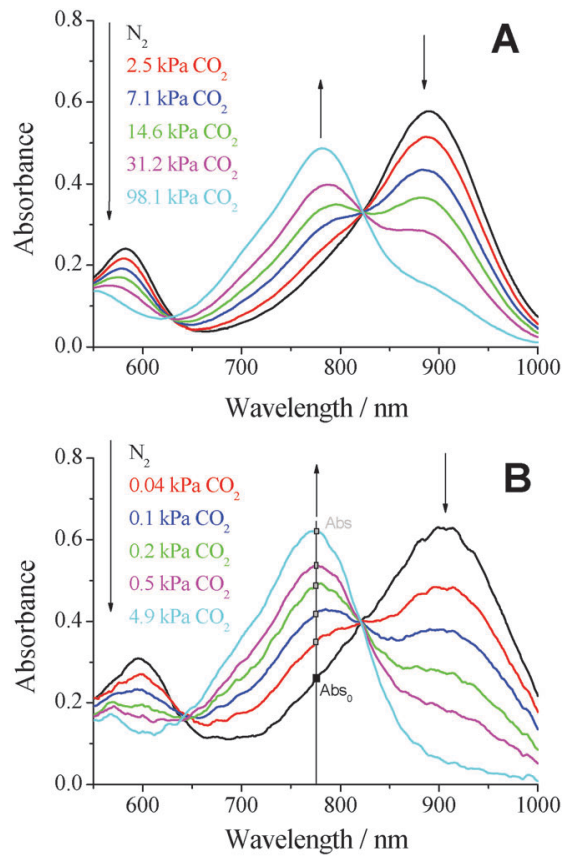

Fig. 2 Absorption spectra of optical carbon dioxide sensors based on (A) the di-Cl-di-OH-complex and (B) the di- $\mathrm{CH}_{3}-\mathrm{di}-\mathrm{OH}$-complex in $\mathrm{EC} 49$ (base: $\mathrm{TOAOH}$ ) at $25^{\circ} \mathrm{C}$ at various $\mathrm{pCO}_{2}$ values. 

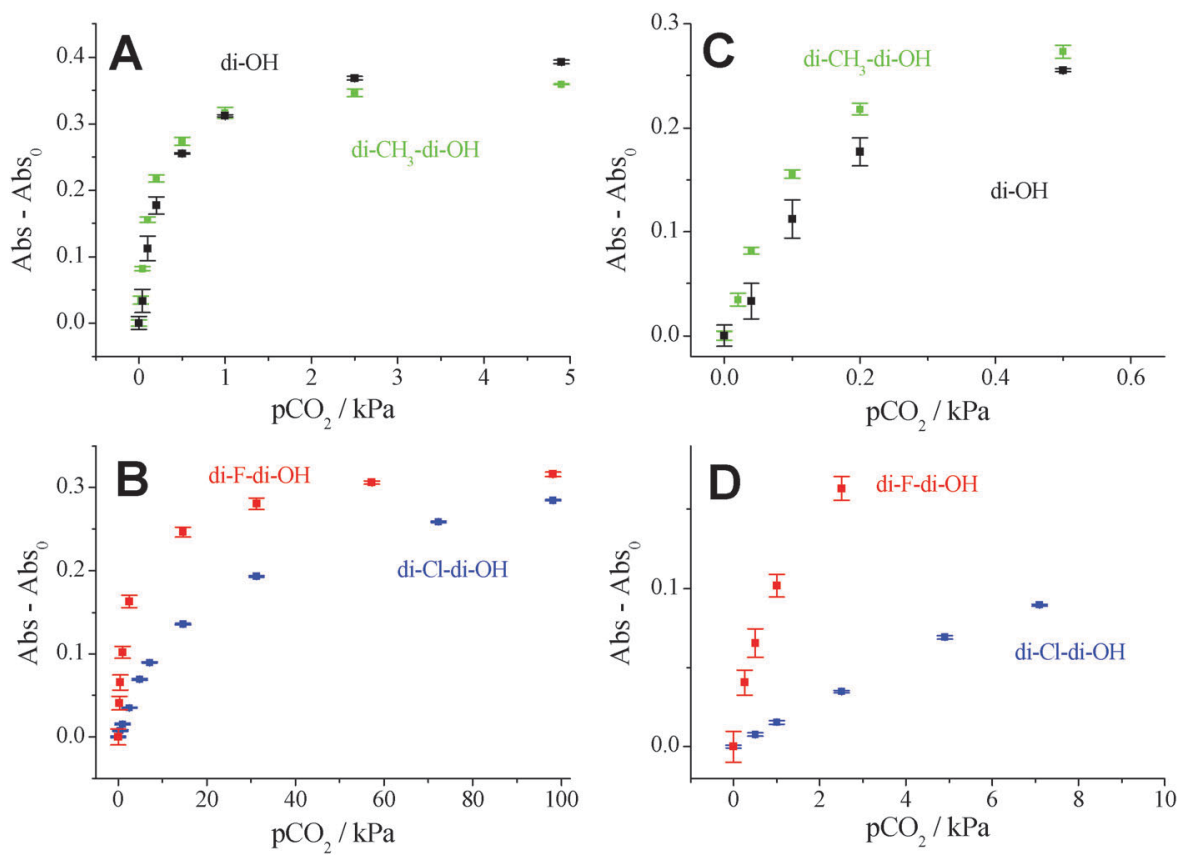

Fig. 3 (A) Calibration curves (absorption-absorption at $\mathrm{O} \mathrm{kPa}$ of the mono-anionic form) for the carbon dioxide sensors based on the di-OH-complex (black) and the di- $\mathrm{CH}_{3}$-di-OH-complex (green) and (B) di-Cl-di-OH-complex (blue) and the di-F-di-OH-complex (red) $25^{\circ} \mathrm{C}$ under humid conditions with the respective "zoom-in" sections (C and D).

and enabled measurements up to $100 \% \mathrm{CO}_{2}$. These great differences in sensitivity lead to a broad range of applications, varying from food packaging and capnography for di-F-di-OH and di-Cl-di-OH complexes to environmental monitoring for di-OH and di- $\mathrm{CH}_{3}$-di-OH complexes.

Fig. 3 shows the increasing absorption of the mono-anionic

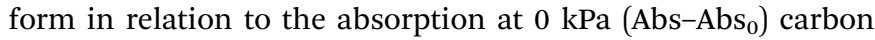
dioxide (see Fig. 2B). The higher the sensitivity of the sensor, the steeper the respective calibration curves, as shown in Fig. 3, and the lower the amount of carbon dioxide necessary to fully protonate the sensor. Sensors based on the di-Cl-di-OH-complex and the di-F-di-OH-complex showed limits of detection (LOD) of $0.19 \mathrm{kPa}$ and $0.18 \mathrm{kPa}$, respectively. However, determining the LOD value for very sensitive sensors can be very challenging. For measurements of low levels of carbon dioxide the measuring system (gas mixer, gas lines, flow cell, etc.) has to be completely decarbonized, which is very difficult to achieve in reality. Especially for atmospheric levels of $p \mathrm{CO}_{2}(0.04 \mathrm{kPa} \approx$ $400 \mathrm{ppm}$ in the gas phase $\approx 13.6 \mu \mathrm{mol} \mathrm{l}^{-1}$ in water at $298.15 \mathrm{~K}$ ) and below, traces of environmental carbon dioxide disturbed the measurements for sensors based on the di- $\mathrm{CH}_{3}$ - $\mathrm{di}-\mathrm{OH}$ complex and the di-OH-complex. Hence, the determined LODs for these two complexes $(0.011 \mathrm{kPa}$ for $\mathrm{di}-\mathrm{OH}$ and $0.007 \mathrm{kPa}$ for di- $\mathrm{CH}_{3}$-di-OH) were only rough estimations.

Photodegradation profiles of the carbon dioxide sensors were obtained from the absorption spectra after illuminating the sensor foils with a high-power LED array $\left(\lambda_{\max } 458 \mathrm{~nm}\right)$. For comparison, the state-of-the-art indicator dyes such as $m$-cresolpurple, thymol-blue and HPTS were used (ESI, $\dagger$ Fig. S1). The photostability of both the mono-anionic and the di-anionic form were investigated. Therefore, the cuvette was filled either with pure carbon dioxide (mono-anionic form) or with pure nitrogen (di-anionic form). Clearly, all of the di-OH-aza-BODIPY dyes showed outstanding photostability, much better than the reference indicators embedded in the same ethyl cellulose matrix. After $1.5 \mathrm{~h}$ of illumination the presented dyes showed hardly any photobleaching effects for both the mono-anionic and di-anionic forms, whereas $m$-cresol-purple (neutral form), thymol-blue (neutral form) and HPTS (only anionic form) were degraded to less than $80 \%$. The anionic forms of $m$-cresolpurple and thymol-blue were even less photostable than there neutral forms (ESI, $\dagger$ Fig. S1).

\section{Luminescence-based ratiometric read-out using IFE (inner-filter effect) based sensors}

Read-out of the planar optodes and fibre-optic sensors based on colorimetric systems is significantly more challenging than that of the luminescent systems. The inner-filter effect (IFE) was made use of in order to enable read-out via luminescence. Additionally to the first layer containing the absorption-based indicator dye along with TOAOH in ethyl cellulose, a second layer containing the secondary emitters was used. ${ }^{42}$ It included the pH-insensitive di-butoxy-complex entrapped in PS-particles as a fluorophore and Egyptian blue (EB) as a phosphor, both embedded in Hyflon AD 60. The absorption spectra of the di-OH-complex and the emission spectra of the secondary emitters are shown in Fig. 4A. Here, the broad emission band of the phosphor (EB) overlaps with the absorption spectrum of the di-anionic form of the indicator and the emission band of the fluorophore (di-butoxy-aza-BODIPY-complex) overlaps with the absorption spectrum of the mono-anionic form of the indicator. The isosbestic point of the di-OH-indicator is located at 

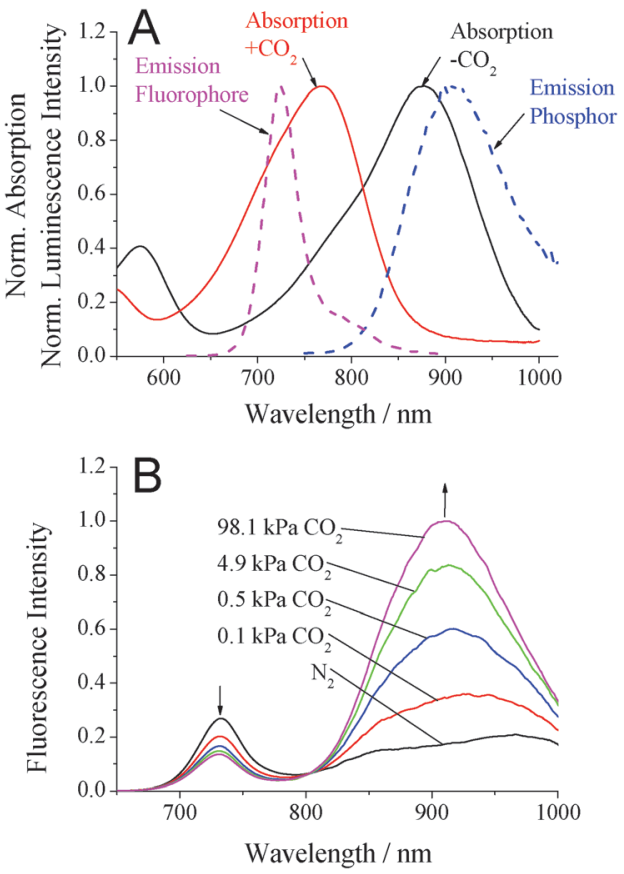

Fig. 4 (A) Emission spectra ( $\lambda_{\text {exc }} 610 \mathrm{~nm}$ ) of Egyptian blue (EB; blue dashed line; "Emission Phosphor") and the di-butoxy-complex (dissolved in tetrahydrofuran; magenta dashed line; "Emission Fluorophore"); absorption spectra of the sensor based on the di-OH-complex in the absence (black line) and presence (red line) of carbon dioxide at $25^{\circ} \mathrm{C}$. (B) Emission spectra $\left(\lambda_{\text {exc }} 610 \mathrm{~nm}\right)$ of a carbon dioxide sensor based on the di-OH complex and inner-filter effect read-out at $25{ }^{\circ} \mathrm{C}$ under humidified conditions.

$610 \mathrm{~nm}$ and represents an ideal wavelength for exciting the secondary emitters matching the maxima of the red LEDs available $(605,617 \mathrm{~nm})$. The fluorescence spectra of the sensor based on the combination of EB, the di-butoxy-complex and the non-substituted di-OH indicator are shown in Fig. 4B. Emission peaks in the absence $\left(\lambda_{\max } 913 \mathrm{~nm}\right)$ and presence $\left(\lambda_{\max } 738 \mathrm{~nm}\right)$ of carbon dioxide were well observable. Hence, luminescencebased ratiometric read-out becomes possible. This can be realized either by using two emission filters isolating the respective components or by measuring the luminescence phase shift. In fact, the phase shift for luminescent Egyptian blue is $55.8^{\circ}$ at $2000 \mathrm{~Hz}$ and the phase shift of the fluorophore is 0 at this modulation frequency.

\section{Carbon dioxide production/consumption of a Hebe plant}

The applicability of the presented carbon dioxide sensors is demonstrated by showing the respiration of a Hebe plant. The Hebe plant in soil, a carbon dioxide sensor based on the di- $\mathrm{CH}_{3}$ di-OH-complex and an oxygen trace sensor were placed in a desiccator. The desiccator was purged for $15 \mathrm{~min}$ with a gas mixture of $2 \%$ oxygen in nitrogen (in order to achieve better dynamics when measuring with an optical oxygen sensor compared to air saturation) and then closed tightly. During the measurement the setup was alternately kept in darkness and illuminated for $30 \mathrm{~min}$ using three halogen lamps. According to these illumination sequences the production/consumption of
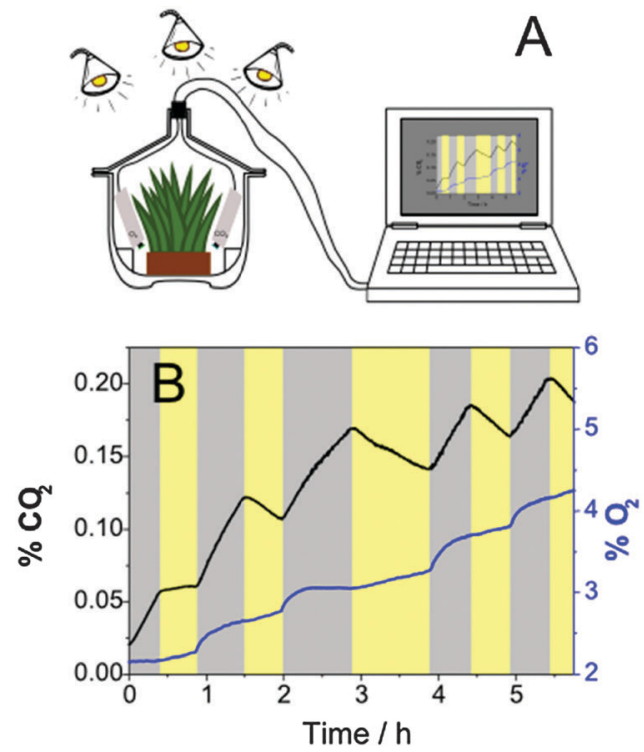

Fig. 5 (A) Experimental set-up and (B) carbon dioxide and oxygen dynamics in a desiccator containing a Hebe plant during illumination (yellow zones) and in darkness (gray zones).

carbon dioxide was observed (Fig. 5). In darkness an increase of carbon dioxide occurred due to respiration, whereas during illumination the concentration of $\mathrm{CO}_{2}$ decreased. Over the whole measurement more $\mathrm{CO}_{2}$ was produced than consumed which may be due to stress-induced respiration of the Hebe plant. Corresponding to the applied light sequences also the oxygen concentration was affected. Note that over the whole experiment the oxygen concentration was increasing which can be explained by slow diffusion of oxygen into the desiccator. Surprisingly, oxygen concentration did not increase significantly during the light phase, but it increased abruptly immediately after the light was switched off, reaching a plateau after about $30 \mathrm{~min}$ (Fig. 5). This effect may be attributed to the storage of generated oxygen in the plant and its release in the beginning of the dark phase. After this time the equilibrium between oxygen consumption during respiration and oxygen diffusion from outside is reached. As can be seen, the same phenomenon is observed if both the light and dark cycles are extended to $60 \mathrm{~min}$ (see hours 2 to 4 in Fig. 5). The above plant behavior is beyond the scope of the paper and calls for more detailed investigation.

\section{Conclusion}

A new class of colorimetric pH-sensitive indicators for carbon dioxide sensors has been presented. The di-OH-aza-BODIPY dyes show characteristic $\mathrm{CO}_{2}$-dependent absorption spectra in the near-infrared region. In addition to the remarkable photostability of the indicators and the high molar absorption coefficients, the dynamic ranges of the sensors can be tuned via electron-donating and electron-withdrawing substituents. This enables a broad range of applications from environmental monitoring to food packaging or capnography. The sensors 
based on di- $\mathrm{CH}_{3}$-di-OH-aza-BODIPYs are the most sensitive sensors ever reported and resolve well below atmospheric $\mathrm{CO}_{2}$ levels. The absorption-modulated inner-filter effect was used to enable referenced luminescence-based ratiometric read-out. As an example the production/consumption of carbon dioxide of a Hebe plant was demonstrated.

\section{Acknowledgements}

This work was supported by 7th framework EU projects ECO2 (project number 265847) and SenseOCEAN (project number 614141).

\section{Notes and references}

1 D. Zhao, D. Miller, X. Xian, F. Tsow and E. S. Forzani, Sens. Actuators, B, 2014, 195, 171-176.

2 A. Mills, A. Lepre and L. Wild, Sens. Actuators, B, 1997, 39, 419-425.

3 S. Trivedi, H. Mehta and R. Kashyap, Indian J. Crit. Care Med., 2014, 18, 348.

4 B. Rost, I. Zondervan and D. WolfGladrow, Mar. Ecol.: Prog. Ser., 2008, 373, 227-237.

5 S. C. Doney, V. J. Fabry, R. A. Feely and J. A. Kleypas, Annual Review of Marine Science, Annual Reviews, Palo Alto, 2009, vol. 1, pp. 169-192.

6 A. E. Punt, D. Poljak, M. G. Dalton and R. J. Foy, Ecol. Modell., 2014, 285, 39-53.

7 K. E. Fabricius, C. Langdon, S. Uthicke, C. Humphrey, S. Noonan, G. De'ath, R. Okazaki, N. Muehllehner, M. S. Glas and J. M. Lough, Nat. Clim. Change, 2011, 1, 165-169.

8 P. Puligundla, J. Jung and S. Ko, Food Control, 2012, 25, 328-333.

9 B. Weigl, A. Holobar, W. Trettnak, I. Klimant, H. Kraus, P. Oleary and O. Wolfbeis, J. Biotechnol., 1994, 32, 127-138.

10 T. Beuermann, D. Egly, D. Geoerg, K. I. Klug, W. Storhas and F.-J. Methner, J. Biosci. Bioeng., 2012, 113, 399-405.

11 A. G. Carroll, R. Przeslawski, L. C. Radke, J. R. Black, K. Picard, J. W. Moreau, R. R. Haese and S. Nichol, Cont. Shelf Res., 2014, 83, 116-128.

12 A. Mills, S. Hodgen, Adv. Concepts Fluoresc. Spectrosc. Pt Small Mol. Sens., 2005, vol. 9, pp. 119-161.

13 J. Zosel, W. Oelßner, M. Decker, G. Gerlach and U. Guth, Meas. Sci. Technol., 2011, 22, 072001.

14 M. Clegg, C. Sullivan and J. Eastin, Plant Physiol., 1978, 62, 924-926.

15 R. Arieli, O. Ertracht and Y. Daskalovic, J. Appl. Physiol., 1999, 86, 647-650.

16 D. García-Fresnadillo, M. D. Marazuela, M. C. MorenoBondi and G. Orellana, Langmuir, 1999, 15, 6451-6459.

17 Y. Liu, Y. Tang, N. N. Barashkov, I. S. Irgibaeva, J. W. Y. Lam, R. Hu, D. Birimzhanova, Y. Yu and B. Z. Tang, J. Am. Chem. Soc., 2010, 132, 13951-13953.
18 R. Ali, T. Lang, S. M. Saleh, R. J. Meier and O. S. Wolfbeis, Anal. Chem., 2011, 83, 2846-2851.

19 S. Pandey, S. N. Baker, S. Pandey and G. A. Baker, Chem. Commun., 2012, 48, 7043-7045.

20 W. Hong, Y. Chen, X. Feng, Y. Yan, X. Hu, B. Zhao, F. Zhang, D. Zhang, Z. Xu and Y. Lai, Chem. Commun., 2013, 49, 8229-8231.

21 X. Xie, M. Pawlak, M.-L. Tercier-Waeber and E. Bakker, Anal. Chem., 2012, 84, 3163-3169.

22 L. Q. Xu, B. Zhang, M. Sun, L. Hong, K.-G. Neoh, E.-T. Kang and G. D. Fu, J. Mater. Chem. A, 2013, 1, 1207-1212.

23 Q. Xu, S. Lee, Y. Cho, M. H. Kim, J. Bouffard and J. Yoon, J. Am. Chem. Soc., 2013, 135, 17751-17754.

24 A. Mills, Q. Chang and N. Mcmurray, Anal. Chem., 1992, 64, 1383-1389.

25 A. Mills and L. Monaf, Analyst, 1996, 121, 535-540.

26 R. N. Dansby-Sparks, J. Jin, S. J. Mechery, U. Sampathkumaran, T. W. Owen, B. D. Yu, K. Goswami, K. Hong, J. Grant and Z.-L. Xue, Anal. Chem., 2010, 82, 593-600.

27 O. S. Wolfbeis, B. Kovács, K. Goswami and S. M. Klainer, Microchim. Acta, 1998, 129, 181-188.

28 C. von Bultzingslowen, A. K. McEvoy, C. McDonagh, B. D. MacCraith, I. Klimant, C. Krause and O. S. Wolfbeis, Analyst, 2002, 127, 1478-1483.

29 O. Oter, K. Ertekin and S. Derinkuyu, Talanta, 2008, 76, 557-563.

30 S. M. Borisov, C. Krause, S. Arain and O. S. Wolfbeis, Adv. Mater., 2006, 18, 1511-1516.

31 N. B. Borchert, J. P. Kerry and D. B. Papkovsky, Sens. Actuators, B, 2013, 176, 157-165.

32 S. Schutting, S. M. Borisov and I. Klimant, Anal. Chem., 2013, 85, 3271-3279.

33 S. Schutting, I. Klimant, D. de Beer and S. M. Borisov, Methods Appl. Fluoresc., 2014, 2, 024001.

34 Z. Xu, A. Rollins, R. Alcala and R. E. Marchant, J. Biomed. Mater. Res., 1998, 39, 9-15.

35 R. C. Hunter and T. J. Beveridge, Appl. Environ. Microbiol., 2005, 71, 2501-2510.

36 K. W. Spitzer, R. L. Skolnick, B. E. Peercy, J. P. Keener and R. D. Vaughan-Jones, J. Physiol., 2002, 541, 159-167.

37 V. K. Ramshesh and J. J. Lemasters, in Mitochondrial Bioenergetics: Methods and Protocols, ed. C. M. Palmeira and A. J. Moreno, 2012, vol. 810, pp. 243-248.

38 T. Jokic, S. M. Borisov, R. Saf, D. A. Nielsen, M. Kühl and I. Klimant, Anal. Chem., 2012, 84, 6723-6730.

39 S. M. Borisov, K. Gatterer and I. Klimant, Analyst, 2010, 135, 1711-1717.

40 M. S. Briggs, D. D. Burns, M. E. Cooper and S. J. Gregory, Chem. Commun., 2000, 2323-2324.

41 M. E. Cooper, S. Gregory, E. Adie and S. Kalinka, J. Fluoresc., 2002, 12, 425-429.

42 S. M. Borisov and I. Klimant, Anal. Chim. Acta, 2013, 787, 219-225. 
43 N. Nakamura and Y. Amao, Anal. Bioanal. Chem., 2003, 376, 642-646.

44 Y. Amao and N. Nakamura, Sens. Actuators, B, 2004, 100, 347-351.

45 I. M. Perez de Vargas-Sansalvador, M. A. Carvajal, O. M. Roldan-Munoz, J. Banqueri, M. D. Fernandez-Ramos and L. F. Capitan-Vallvey, Anal. Chim. Acta, 2009, 655, 66-74.
46 S. M. Borisov, C. Wuerth, U. Resch-Genger and I. Klimant, Anal. Chem., 2013, 85, 9371-9377.

47 M. J. Hall, S. O. McDonnell, J. Killoran and D. F. O'Shea, J. Org. Chem., 2005, 70, 5571-5578.

48 A. Gorman, J. Killoran, C. O'Shea, T. Kenna, W. M. Gallagher and D. F. O'Shea, J. Am. Chem. Soc., 2004, 126, 10619-10631. 